\title{
Construction of Higher Inclusive Education Mode for the Disabled -- A Case Study of Sichuan Province
}

\author{
Xiaolin Liu \\ Chengdu Medical College, Chengdu, China
}

Keywords: The disabled; higher education; inclusion; Sichuan Province.

\begin{abstract}
In recent years, our government has been continuously supporting the construction of higher inclusive education for the disabled, which is beneficial for the development of higher education for those in Sichuan Province. Overall, the higher education for the disabled in Sichuan Province remained low-level and its development is unbalanced. This paper analyzes the present situation of higher education for the disabled in Sichuan Province, as well as its demands, policy supporting and specialty setting and so on. This paper also explores the approaches to construct the inclusive education with an intention to provide suggestions for the development of inclusive education mode in Sichuan Province.
\end{abstract}

\section{Introduction}

In 2015, the Ministry of Education issued Thematic report on the evaluation of special education. This report referred to the exploration into how colleges and universities provide the disabled with supporting services for their inclusive education. Inclusive education is original from the Western, which proposes the students with disabilities should accept education in ordinary schools to the greatest extent. Therefore, these special children could fit in ordinary educational institutions and mainstream society. It advocates inclusion instead of isolation. Sichuan Province has more than six million people with disabilities. It shows great significance of constructing and developing the higher special education and promoting the inclusive education, which would contribute to the work for persons with disabilities in central and western regions of China.

\section{Present Situations of Higher Special Education in Sichuan Province}

On the whole, the higher special education of the people with disabilities in Sichuan Province is still in a low and unbalance developmental stage. According to the Second National Sample Survey on Disability, there are totally 6.225 million disabled people in the whole province, which accounts for $7.57 \%$ of its population. The number of the disabled in Sichuan is the largest in China. And the proportion of the disabled ranks the second in the whole country. Persons with disabilities account for one fifth families within the province. However, only 36,600 of the disabled gain a university degree (referring to junior college and above), which accounts for $0.59 \%$ of all persons with disabilities[ Report of the Second National Sample Survey on Disability carried out in cities and counties of Sichuan Province [M]. Press: Office of the Second National Sample Survey on Disability of Sichuan Province, 2007.].

The connection between intermediate special education and higher special education is not enough. According to the main bulletin data of Second National Sample Survey on Disability of Sichuan Province (File No. 2), about 209, 900 people with disabilities have received high school education (including specialized secondary education). And only 36,600 of them gain a university degree (referring to junior college and above)[ Report of the Second National Sample Survey on Disability carried out in cities and counties of Sichuan Province [M]. Press: Office of the Second National Sample Survey on Disability of Sichuan Province, 2007.].

The situations that different types of the disabled receiving higher education are different. In the seven classifications of the disabled, the number of persons with physical disabilities receiving higher 
education is the largest, followed by vision and hearing disabilities. Only few of the disabled with other disabilities have receiverd vocational and higher education.

\section{Feasibility Analysis on the Development of Higher Special Education in Sichuan Province}

Policy supporting. In recent years, the state has issued laws and regulations on special education for persons with disabilities. Provinces and municipalities also develop their regional policies on special education. To promote special education for the disabled, Sichuan Province has issued lots of policies. Firstly, in terms of the overall planning of special education, Sichuan Province has forwarded The Office of the Sichuan Provincial People' s Government on the implementation plan to improve special education carried out by Department of Education and other departments (2014-2016). The outline of the Twelfth Five-year Plan for the career development of the disabled in Sichuan Province has also been issued. Secondly, in terms of higher special education, Sichuan Province has issued Sichuan Provincial people' s Government on the implementation of crucial three-year vocational education programs (Sichuan Provincial people’ s Government (2008) No. 14), and separate enrollment policy for the disabled. Thirdly, in terms of teacher training, Sichuan Normal University and Chongqing Normal University are listed in the reform project of training excellent teacher. A series of policies for the development of higher special education provides a solid foundation.

Initial attempt on the separate enrollment of higher special education. In 2015, the higher education colleges in Sichuan Province accepted persons with disabilities for the first time. This is carried out by the cooperation of Leshan Normal University and Sichuan Zhixiang Vocational School. It recruits the junior high school graduates in Sichuan. The whole learning takes five years. The first three years is done in Sichuan Zhixiang Vocational School. After passing the examination, the students are allowed to study in Leshan Normal University. And finally they would gain vocational college diploma awarded by Leshan Normal University. For the first time enrollment in 2015, it totally recruited 50 students majoring in hearing impairment art and design. 22 of them are male while 28 of them are female. The eldest is 21 years old while the youngest is 14 years old. They came from nine cities (counties) of the province. The separate enrollment of higher special education helps the disabled to accept higher special education, improve their self-development capacity to survive and provide more opportunities to fit in our society. These will greatly promote the exploration into the inclusive education of higher special education for persons with disabilities in Sichuan.

Practices at home and abroad. Over a long period, all the countries around the world are developing theories and practices on special education, which form a lot of inclusive education models. For instance, the United States adopts consulting model, team teaching model and assistant service model. Japan adopts itinerant teacher model, resource classroom model and teaching assistant model; the United Kingdom adopts intersectional collaboration model[WANG De-yi. Comparison of the Curriculum Setting Model of Higher Vocational Education for the Disabled in China, the United States and Japan [J], CHINA AFTER SCHOOL EDUCATION, 2011.5.]. After years of practice and exploration, some local inclusive education models, such as, learning in regular class, special education class, combining medicine and education and so on, have been formed. Obviously, there are no standard practice examples of inclusive education. Therefore, we should consider the local economic and social development, as well as the education requirements of persons with disabilities, and explore the development of special education, so that we could promote special education and general education to be inclusive.

\section{Approaches to Implement Inclusive Education}

To provide supporting policies and form a linkage mechanism. Higher special education for the disabled is an important part of national education. Currently, the state has issued Regulations of Education of People with Disabilities, The Outline of the Twelfth Five-year Plan for the Career Development of the Disabled in China, Department of Education and other Departments' Views on 
Accelerating the Development of Special Education Forwarded by General Office of the State Council, Implementation on Promoting Special Education (2014-2016). All these documents are holistic plans instead of specific implementations. In order to ensure the smooth development of persons with disabilities in higher education, on one hand, Sichuan Province should introduce the specific laws and regulations of higher education for persons with disabilities and clearly stipulate the higher education approaches and forms, as well as the rights, obligations and responsibilities of relevant responsible subjects, so that we could ensure the implementation of higher education. On the other hand, inclusive education requires the united power of all parties. The government departments should also work with each other and form a linkage mechanism instead of working alone. In addition, we should pay more attention to the participation and cooperation of the workers from the institutes of education, health, social services and volunteer organizations, the children and their parents. Therefore, we could together support and promote the development of special higher inclusive education.

To integrate educational resources and merge the healthy with the disabled. Inclusive education is to create inclusive schools based on receive and affiliation. In China, people with disabilities gain their degrees from independently set special universities, colleges and departments under the universities of special education, adult education, TV universities, self-taught examinations, School of Distance Education, networking colleges and other education institutions. Thus, they could learn, accept their education, and ultimately gain their diploma. In practice, while merging the disabled students with the ordinary schools, we cannot lower the standards of ordinary higher education to exchange the opportunities of the enrollment of the disabled. We cannot regard the disabled as those without the learning ability. We should reasonably consider the strength and weakness of their own learning abilities, so that they could choose different higher special education forms based on specific conditions.

Sichuan has rich educational resources. It has five key universities, twenty-six ordinary colleges, twenty-six independent colleges, forty-nine higher vocational colleges, thirty-seven public vocational colleges and twelve private vocational colleges, and dozens of TV universities, self-taught examinations, networking colleges. While making the best use of existing university teaching resources, we could bring higher education for persons with disabilities into the existing education system and establish special education majors in the affordable universities and colleges, normal universities, education colleges, vocational colleges. Meanwhile, we could adopt self-taught examinations, distance education and " $3+2$ " model to cultivate the disabled and help more people with disabilities accept higher education.

To strengthen the construction of qualified teachers and improve the education level. Currently, three universities and colleges in Sichuan Province, Leshan Normal University, Chengdu University and Sichuan University of Arts and Science, have set special education majors. However, the number of students enrolling in universities is quite small. Three schools have only recruited less than 100 students per year, and their future employment is unstable. Those are capable of special education are very scarce, which is unable to meet the requirements of constructing the special education within the province.

In terms weak teachers resources, on one hand, the educational departments should focus on and support the teachers' training of special education, expand the special education enrollment, improve the professional education level, implement curriculum reforms, deal with the internship and recruitment of the graduates from special education schools and institutions. On the other hand, we should strengthen the training of special education teachers. By combining with the present status and planning of provincial special education, we should construct a training system of uniting theoretical guidance and skills training, academic upgrading and professional knowledge, regular training and classification training, which would contribute to the scientific and comprehensive training of the in-service teachers.

To expand major setting and promote curriculum reforms. In the past five years, the disabled students in Sichuan Province which are admitted to higher education institutions are mainly physically disabled, blind and deaf. The majors they could choose are limited. The hearing-impaired 
disabled students mainly choose art and design, computer science. The visually impaired disabled students mainly choose music, acupuncture and massage. Comparatively, the physically disabled students have more majors. While giving lessons, the disabled and the ordinary ones are almost the same, which has not shown the speciality of education.

While setting majors and curriculums, we can learn from the University of Tsukuba, Japan short-term. It is a higher education institution which recruits vision-impaired and hearing-impaired students. It has established the majors of design, machinery, construction engineering, electronic information science, physiotherapy and acupuncture. By cooperating with its well-known domestic companies, such as Toshiba, Panasonic, Hitachi and so on, they establish a training base. The professional practice courses account for 51.1\%. They build a school-enterprise cooperation training model, and focus on the training of people with disabilities. Another example is the Deaf Rochester Institute of Technology in the United States. While they are setting majors and curriculums, the market and job requirements are taken into consideration. By combined with the actual demand of jobs, they provide multiple majors, for instance, design, art, science, industry, medicine, biology, economy and so on. These majors are both practical and professional.

While setting the majors of higher special education in Sichuan Province, we should firstly consider the actual future employment of the persons with disabilities and pay attention to the training of social viability of persons with disabilities. In addition, we should investigate the demands of local economic and social development, as well as the job requirements. And then we can expand the range of the majors for the disabled.

\section{The Problems of Developing Inclusive Education}

Huge economic investment and heavy financial burden. Sichuan Province has forwarded The Office of the Sichuan Provincial People' s Government on the implementation plan to improve special education carried out by Department of Education and other departments (2014-2016). The document proposes that the public fund budget for the special education in compulsory education stage should come up to 6000 yuan per year for each student within three years. That is, it should come up to 4000 yuan in 2014; come up to 5000 yuan in 2015; come up to 6000 yuan in 2016. The situation of learning in regular class and special education class and so on are also based on this standard. The required fund is taken on by the central, provincial and municipal and county finance a proportional share, which is based on the funds guarantee mechanism of rural compulsory education." There are more than six million people with disabilities in Sichuan. About 30\% of them are zero to thirty years old. If all the special education fund is taken on the government, it would be a heavy financial burden. Thus, while developing special education, we need to ask the community for kelp.

More persons with disabilities in rural areas and lower education level. The population of the disabled in urban areas in Sichuan is $1,381,100$, accounting for $22.19 \%$. However, the population of the disabled in rural areas in Sichuan is 4,841,900, accounting for $77.81 \%$. Large numbers of the disabled in rural areas involve many families with low income. In addition, the economic development and the education levels in the counties are different, which also includes the rural areas inhabited by ethnic minorities. Therefore, how to develop the education for the disabled in rural areas has always been a tough problem.

The unstable number of the disabled who receive education. Our country has been paying attention to the development of all the work on the disabled. However, their living conditions have not improved as expected. In recent years, in Sichuan Province, the number of students with disabilities tends to decrease with the increase of grades. The loss of the students in school is quite large.

\section{Conclusions}

Inclusive education advocates that the students with disabilities should accept education in ordinary schools to the greatest extent. Therefore, these special children could fit in ordinary 
educational institutions and mainstream society. This contributes to educational equity to some extent. In recent years, the state has been continuously supporting the construction of higher inclusive education for the disabled. Based on our own conditions, our Sichuan Province should follow the trend of social development, learn from the successful experience at home and abroad, construct our own system of inclusive education for persons with disabilities and improve the vulnerable people' s plight of survival and development. These would all realize the fairness and justice of education and promote the harmonious education development for the disabled..

\section{Acknowledgement}

Fund project: This project, Research on Construction and Development of Higher Inclusive Education for the Disabled in Sichuan Province (Project No.: SCTJ-2015-C02), is supported by Key Research Base for Philosophy and Social Science of Sichuan Province and Special Education Development Research Center of Sichuan Province in 2015. Liu Xiaolin, the author, is the leader of this project.

\section{References}

[1] SHE Wan-bin. Special education major in colleges SWOT analysis and development strategy of Sichuan Province [J]. Journal of Zhaowuda Mongolian Teachers College, 2013, 34 (11).

[2] ZHUANG Shu-fan \& ZHANG Dai-zhi. Research and Practice on the Development Model of Higher Special Education Innovation [J]. Journal of Changchun University, 2013, 23(6).

[3] 2015 China Statistical Yearbook on the Work for Persons with Disabilities, China Statistics Press, August, 2015. 